\title{
On-line liquid quench sampling and UV-Vis spectroscopy for tar measurements in wood gasification process gases ${ }^{\sqrt{3}}$
}

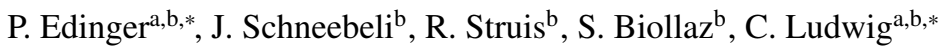 \\ ${ }^{a}$ Ecole Polytechnique Federale de Lausanne (EPFL), ENAC-IIE, 1015 Lausanne (Switzerland) \\ ${ }^{b}$ Paul Scherrer Institut (PSI), ENE, 5232 Villigen PSI (Switzerland)
}

\begin{abstract}
In biomass gasification processes, the formation and handling of tars are of major concern. Robust and versatile analytical tools are needed to on-line monitor tar compound concentrations in process gases from lab- to industrial scale. This study addresses the development and application of an on-line UV-Vis method, based on a liquid quench sampling system. The high sensitivity of this method allows to detect UV-Vis active tar compounds in the low ppmv region. Recorded spectra from the liquid phase were analyzed for their tar composition by means of a classical least squares (CLS) and partial least squares (PLS) approach. The developed method was applied to two case studies, involving a lab-scale tar reformer and a pilot-scale gas scrubber. Quantification results in gases with limited complexity in tar composition showed good agreement with off-line reference methods (GC-FID). The case studies show that the developed method is a rapid, sensitive tool that can be applied for qualitative process monitoring with the added benefit of quantification in gases with a limited number of tar compounds.
\end{abstract}

Keywords: Biomass gasification, Tar, UV-Vis, On-line

\section{Introduction}

The gasification of woody biomass for energy conversion is a viable option to meet future goals to reduce greenhouse gas emissions [1]. The composition of the gas exiting a gasifier depends on the gasification technology, feedstock quality and operation parameters. The wood gas (referred to as producer gas) is mainly composed of $\mathrm{H}_{2}, \mathrm{CO}, \mathrm{CO}_{2}, \mathrm{CH}_{4}$ and $\mathrm{H}_{2} \mathrm{O}$. Besides, it contains several undesired by-products in form of particulate matter, sulphur compounds, $\mathrm{HCl}$, trace elements and tars which can cause severe problems in down-stream equipment [2].

Tars can be defined as hydrocarbons with a molecular weight greater than benzene [3]. They are formed during gasification in a series of complex reactions [4]. Typical concentrations in the raw gas range from $0.01-150 \mathrm{~g} / \mathrm{Nm}^{3}$ [5]. When cooled down, tars can condense while increased temperatures can result in the formation of more complex compounds with higher boiling points. This can cause clogging and fouling of pipes, heat exchangers, particulate filters or other potential

\footnotetext{
The published article can be accessed at http://dx.doi.org/10.1016/j.fuel.2016.06.127.

${ }^{*}$ Corresponding authors

Email addresses: philip.edinger@alumni.ethz.ch (P. Edinger), christian.ludwig@epfl.ch (C. Ludwig) 
down-stream processes, such as fuel cells or catalysts [6]. As a result, tar formation and its control are still considered as one of the major challenges in the implementation of biomass gasification technology [7]. The impact of tars on down-stream equipment is less caused by the lumped sum of tar compounds but rather the tar composition. It is therefore convenient to classify tar compounds based on their condensation behavior into five classes as presented in fig. 1 [8].

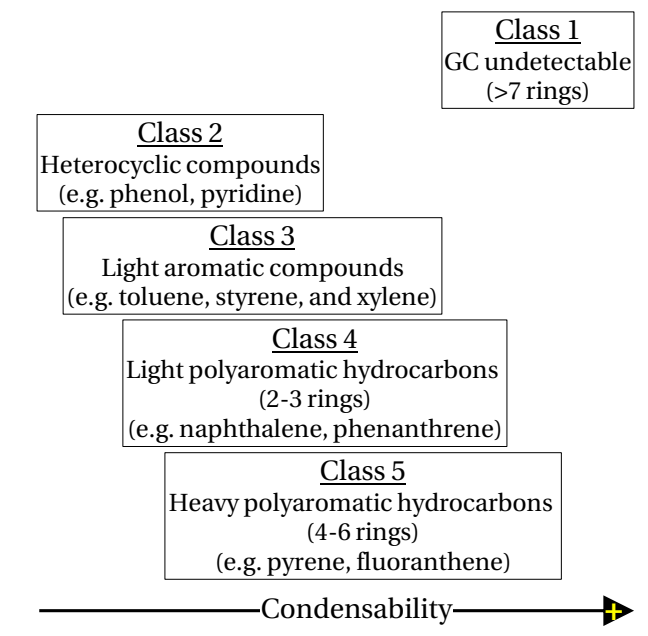

Figure 1: Classification of biomass tar (adapted from [8,9])

Research focuses on the reduction of tar content by a combination or individual use of primary and secondary measures. Primary measures encompass the use of bed materials and catalysts in the gasifier and the optimization of biomass fuel properties, gasifier design as well as operating conditions $[8,10]$. Secondary measures are methods to remove tars in a separate step after gasification. The latter can be further divided into physical and chemical tar removal methods. Physical methods include liquid scrubbers, which require the gas to be cooled down (typically $20-60^{\circ} \mathrm{C}$ ), causing efficiency losses. Chemical methods offer a promising alternative to decrease tar concentrations by thermal cracking (typical temperature range of $1000-1300^{\circ} \mathrm{C}$ ) or the use of catalysts to enhance steam reforming and cracking reactions (typical temperature range of $\left.500-900^{\circ} \mathrm{C}\right)[5,11,12]$.

Regardless of the measure, robust on-line analytical tools are needed in order to correctly assess gasifier performance and tar treatment. Off-line measurement of tar compounds is typically performed by cold solvent trapping (CST) according to the tar protocol [13] or solid phase adsorption (SPA) $[14,15]$. In the CST method, the producer gas is passed through a series of cooled solvent scrubbers, whose content is analysed afterwards. In the SPA method, tar is adsorbed onto a column with a small amount of amino-phase sorbent and later desorbed by a solvent for the analysis of tar compounds. Compared to CST, SPA offers shorter sampling times (ca. 1 min versus ca. $20 \mathrm{~min}$ ), a less complicated sampling procedure and more complete results for most cases [16]. This has led to the wide usage of SPA for determining concentrations of tar compounds. Both methods share the disadvantage of being off-line where the solvent is later analysed by GC techniques (typically GC-MS, GC-FID). The development of on-line analytical tools for the determination of tar compounds in biomass gasification atmosphere has therefore gained considerable attention in recent years. Various measurement systems, based on laser spectroscopy 
(laser-induced fluorescence (LIF), Raman), have been described [17, 18, 19]. Mass spectrometers (MS) in combination with electron impact (EI) ionization as hard ionization method (GC-MS, molecular-beam (MB)) $[20,21,22]$ as well as soft ionization techniques (ion molecule reaction (IMR), single photon ionization (SPI), resonance-enhanced multiphoton ionization (REMPI)) $[23,24,25,26]$, to reduce spectral overlap, were used for tar compound detection. While all above mentioned methods are, in principle, able to obtain quantitative information about the tar composition, they rely on relatively expensive equipment. More cost-effective tar analysers have been developed in form of a tar dew point analyser (TDA) [27] and using methods based on flame ionization detection (FID) [28] and photo ionization detection (PID) [29, 30]. They do not, however, provide an indication on the tar composition.

UV-Vis spectroscopy promises to be a quick and robust, yet economical tool to on-line monitor tar compound concentrations in gases. Most tar compounds have conjugated $\pi$-electron systems and absorb light in the UV-Vis range [31]. Non-aromatic tar compounds, on the other hand, typically adsorb light at wavelengths $(<200 \mathrm{~nm})$ which are instrumentally not easily accessible. The fact that most tar compounds are UV-Vis active has been exploited by previous authors. Patuzzi et al. used an optical cell, fitted with four LEDs, for on-line UV-Vis measurements of tars in pyrolysis off-gas, but resulting only in four point spectra [32]. Based on a calibration with naphthalene, the measured spectra were then analysed in terms of a normalized naphthalene content, neglecting the possible presence of tar compounds with widely different extinction coefficients. Di Marcello et al. collected gas samples from different types of gasifiers according to the aforementioned tar protocol [33]. Absorbance spectra of these samples were subsequently measured off-line by an UV-Vis spectrometer. A univariate calibration, involving the total tar content of the samples, measured by HPLC analysis, and the absorbance at selected wavelengths was successfully performed. Correctness of the predictions will, however, depend on the premise that the tar composition does not change. Qualitative or quantitative information on the individual tar compounds could not be obtained. Using advanced chemometrics (MCR-ALS), Weide et al. were able to obtain qualitative, on-line information on the composition of a changing tar mixture of five compounds [34].

The objective of this work is to establish an on-line UV-Vis method to monitor tar compounds in gases encountered in biomass gasification processes. In the first step, a liquid quench sampling system was adapted for on-line UV-Vis measurements. The employed liquid quench sampling system transfers condensable gas species, including tars, into an organic solvent flow whose absorbance is detected. Measurement in the liquid phase allows for easy calibration, compared to gas phase calibration, where complex instrumentation is needed. Multivariate calibrations, based on classical least squares (CLS) and partial least squares (PLS) regression were applied to enable the quantification of tar compounds in different applications. In the second step, the established method was used in two case studies. The first involved a lab-scale reactor for investigating the decomposition of a defined number of tar compounds across a catalyst. The second case study concerned the effectiveness of a gas scrubber in a pilot-scale wood gasification plant.

\section{Experimental Section}

\subsection{Chemicals}

Pure tar compounds of benzene, toluene (Merck), styrene (Fluka), indene (Sigma-Aldrich) and naphthalene (Riedel-de Haen) for calibration were acquired with a purity $>97 \%$. The solvent 2-propanol was obtained with analytical grade from VWR chemicals. 


\subsection{Sampling System}

On-line measurements of tar compounds were conducted with a liquid quench sampling system, whose basic characteristics have previously been described [35, 36]. A schematic representation of the adapted sampling system is given in fig. 2 .

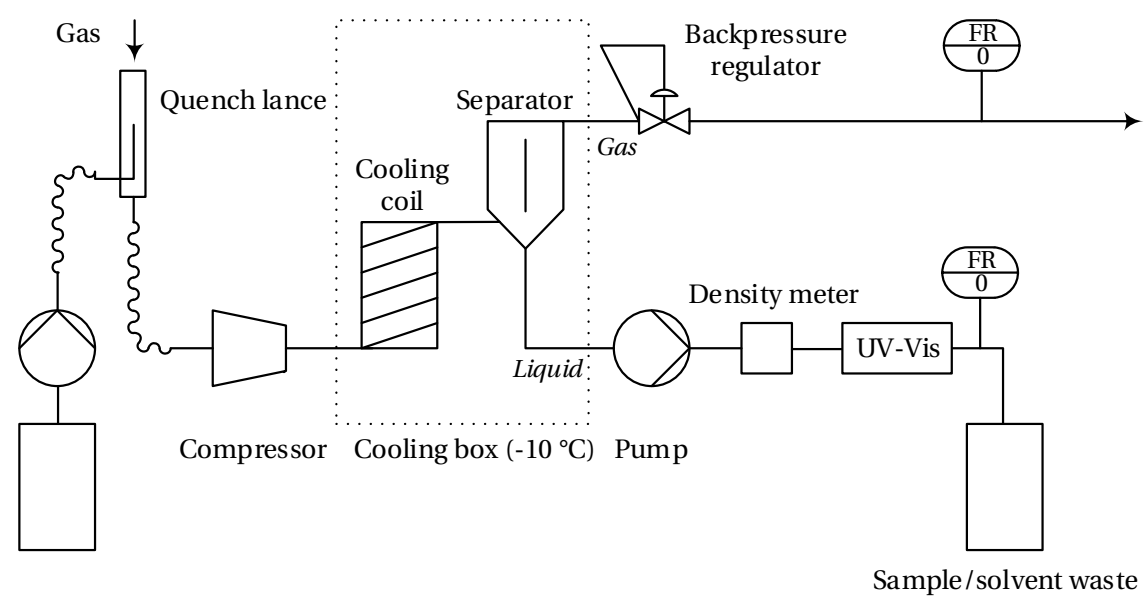

Figure 2: Schema of liquid quench sampling system and on-line analytical instruments. FR refers to flow rate-recording

The sample gas flow is drawn into the quench lance by a pump where it is brought into contact with an organic solvent (2-propanol) fed by a rotary piston pump (Reglo-CPF Analog, Ismatec). The resulting two-phase flow is compressed (N86KN, KNF) to 1 barg, cooled down to approximately $-10^{\circ} \mathrm{C}$ and fed to a separator where gas and liquid phases are separated. Previous experiments have shown that compression and solvation of specific tar compounds of classes 3-5 have negligible effect on the tar composition [37, 38]. It cannot be excluded, however. After a back-pressure regulator, the gas is sent to a custom-made flow-meter and then optionally sent to a $\mu \mathrm{GC}$ (CP 4900, Varian) for analysis of the permanent gas species composition. The liquid stream from the separator is pumped (Ismatec, Reglo-CPF Analog) through a density meter (DMA 35, Anton Paar), a UV-Vis flow-through cell and a custom-made flow meter. The liquid stream can then either be automatically sampled into vials for later off-line analysis or directed to a solvent waste containment. Typical collection times for liquid samples were $20 \mathrm{~min}$. Measured concentrations $c_{i, l i q}$ of condensable species $i$ in the liquid sample phase are related to their corresponding gas phase concentrations $c_{i, g a s}$ by means of eq. (1).

$$
\begin{aligned}
& c_{i, g a s}=\frac{\dot{V}_{i, \text { gas }}^{(S)}}{\dot{V}_{\text {permanent,gas }}^{(S)}+\dot{V}_{\mathrm{H}_{2} \mathrm{O}, \text { gas }}^{(S)}} \\
& =\frac{c_{i, l i q} \dot{V}_{\text {sample,liq }} M_{V}^{(S)}}{\left(\frac{\dot{V}_{\text {permanent,gas }}^{(S)}}{\dot{V}_{\text {sample,liq }}}\right) \dot{V}_{\text {sample }, \text { liq }}+\frac{w_{H_{2} O, l i q} \dot{m}_{\text {sample }}}{\dot{M}_{\mathrm{H}_{2} \mathrm{O}}} M_{V}^{(S)}}
\end{aligned}
$$

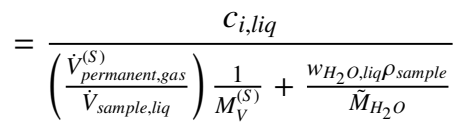


It is assumed that the concentration $c_{i, g a s}$ can be represented by the ratio of the gaseous volume flow $\dot{V}_{i, g a s}^{(S)}$ of species $i$ to a total gas volume flow in the denominator which exclusively consists of the permanent gas species $\dot{V}_{\text {permanent,gas }}^{(S)}$ and steam $\dot{V}_{\mathrm{H}_{2} \mathrm{O} \text {,gas }}^{(S)}$, while other compounds, such as tars, are being neglected. As a result, the gas phase concentration $c_{i, g a s}$ will depend on the liquid phase concentration $c_{i, l i q}$, the ratio $\dot{V}_{\text {permanent,gas }}^{(S)} / \dot{V}_{\text {sample,liq }}$ of gas and liquid flows exiting the separator, the mass fraction of water, $w_{\mathrm{H}_{2} \mathrm{O} \text {, liq }}$, in the liquid flow and the liquid sample density $\rho_{\text {sample. }}$ In this equation, the term $(S)$ refers to standard conditions, $M_{V}^{(S)}$ the molar volume, $\tilde{M}_{\mathrm{H}_{2} \mathrm{O}}$ the molar mass of water and $\dot{m}_{\text {sample }}$ to the mass flow of the liquid sample.

When neglecting the influence of dissolved tar compounds on the density of the liquid sample, the measured density $\rho_{\text {sample }}$ can be used to calculate an estimate of $w_{\mathrm{H}_{2} \mathrm{O} \text {, liq }}$ by means of an algebraic model as presented in eq. (2) (see supplementary information (SI) for detailed discussion).

$$
w_{H_{2} O, \text { liq }}=k_{1}+k_{2} T_{\text {sample }}+k_{3} \rho_{\text {sample }}+k_{4} \rho_{\text {sample }}^{2}
$$

In this equation, $T_{\text {sample }}$ refers to the sample temperature. The parameters $k_{1}$ to $k_{4}$ were obtained from fitting the model to experimental data provided by Egorov et al. [39], who investigated the density of the system 2-propanol-water at atmospheric pressure. The experimentally obtained response surface and residuals are presented in fig. 3. The coefficient of determination of 0.9999 indicates that the experimental data are well represented by the model.

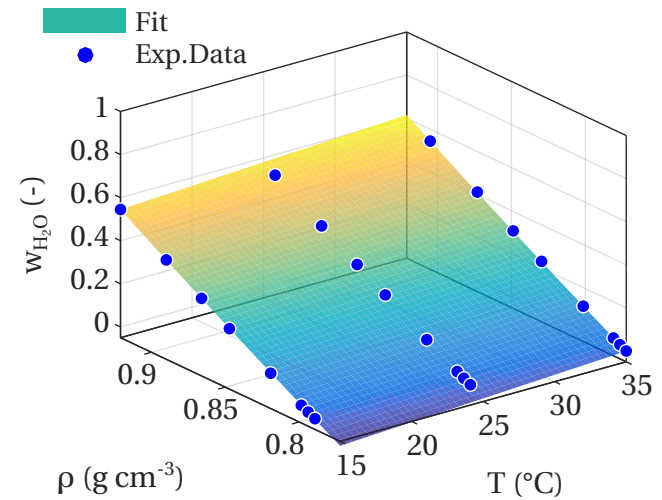

(a)

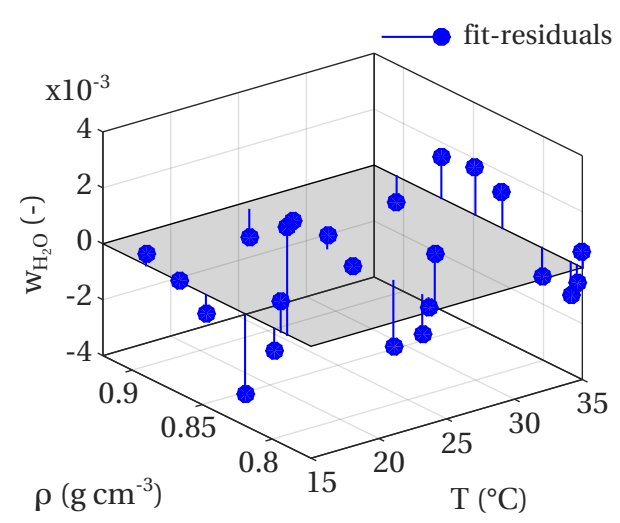

(b)

Figure 3: (a) Experimental data and response surface of the water content of the binary mixture 2-propanol-water as a function of density and temperature; (b) residuals of the fit.

\subsubsection{Response behavior of the liquid quench sampling system}

The response time characteristics of an analytical method can be of importance when transient processes are to be observed. In order to investigate the step response behavior of the sampling system, it was connected to a pipe, constantly flushed by $1 \mathrm{NL} / \mathrm{h}$ of Ar. For comparison, a MS (MAX 300-LG, Extrel) was connected to the same pipe. At time $\mathrm{t}=0,10 \mathrm{ppmv}$ of the sulphur containing heterocyclic compound thiophene were added to the gas stream by means of a mass flow controller (MFC, EL-FLOW, Bronkhorst). The resulting signal responses of the UV-Vis, for wavelength $\lambda=241 \mathrm{~nm}$, and the MS $(\mathrm{m} / \mathrm{z}=84)$ are plotted in fig. 4 . The MS showed a signal 
increase $1 \mathrm{~min}$ after thiophene addition, reaching a stable signal after $4.5 \mathrm{~min}$. The liquid quench sampling system connected UV-Vis on the other hand, had an increase in signal intensity after $7 \mathrm{~min}$ and reached a stable signal only after $17 \mathrm{~min}$. Based on the step response signal $A_{241}$ (absorbance at $241 \mathrm{~nm}$ ) of the sampling system, the mean residence time $t_{\text {mean, res }}$ can be calculated according to eq. (3) [40].

$$
t_{\text {mean }, \text { res }}=\frac{1}{A_{241, \max }} \int_{0}^{A_{241, \max }} t d A_{241}
$$

In this equation, $A_{241, \max }$ refers to the maximum measured absorbance. Assuming a Dirac input to the system, the majority $(90.4 \%)$ of thiophene molecules will pass the UV-Vis detector within \pm 4 min of the calculated mean residence time of $11.5 \mathrm{~min}$.

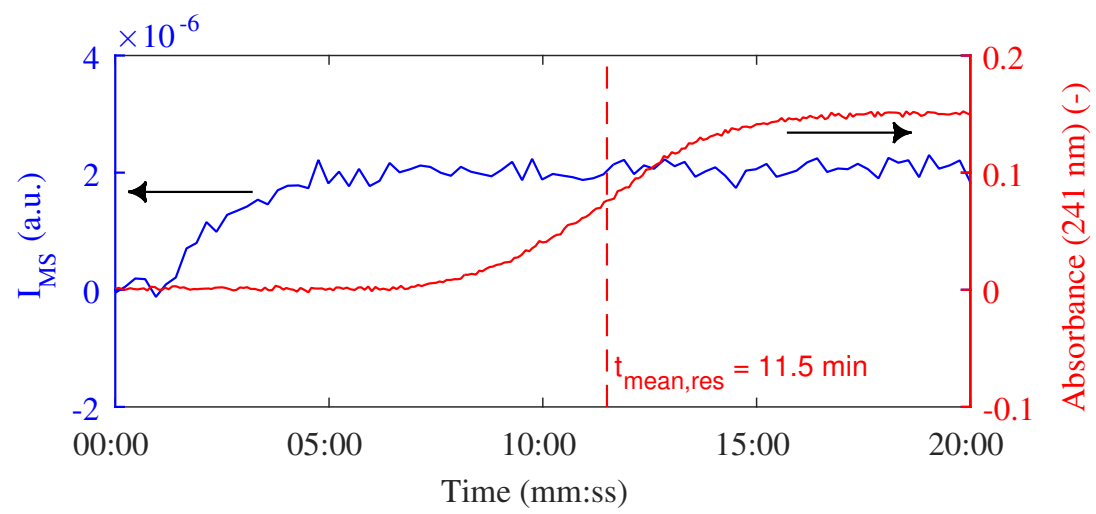

Figure 4: Dynamic response of liquid quench sampling system (red) and a mass spectrometer (blue). The vertical line represents the mean residence time of the sampling system.

\subsection{UV-Vis Apparatus}

On-line UV-Vis spectra were taken in a custom-made flow-through cell (path length $2 \mathrm{~mm}$ ) connected to a deuterium, tungsten-halogen light source (DT-MINI-2-GS, Ocean Optics) and a single beam spectrometer (USB2000+XR1, Ocean Optics) by optical fibers. Spectra were recorded in the range $188-1032 \mathrm{~nm}$ at $0.4 \mathrm{~nm}$ intervals. Typical spectral detection rates were about 0.02-0.03 Hz. Off-line measurements of UV-Vis spectra from collected samples were carried out in a standalone split-beam UV-Vis analyser (Carry 4000, Agilent) fitted with a quartz cell of 10 $\mathrm{mm}$ path length. Spectra were acquired in the range $225-400 \mathrm{~nm}$ at $0.2 \mathrm{~nm}$ resolution. Dilution of samples for off-line analysis was performed with 2-propanol to achieve absorbances below two.

\subsection{Case Studies}

Two case studies were defined to evaluate the described analytical method. A simplified scheme of the experimental set-ups including sampling positions is provided in fig. 5. The first case study (see fig. 5a), called model gas case study, is a laboratory application with a defined gas and mixture of tar compounds. The second case study (see fig. 5b), called real producer gas case study, represents an industrial application. 


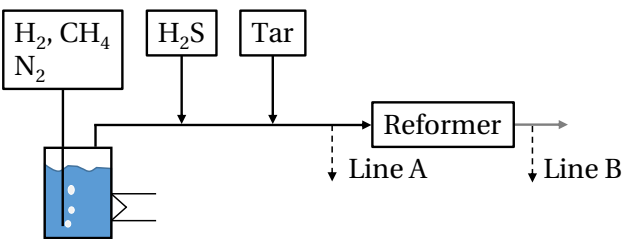

Steam saturator

(a)

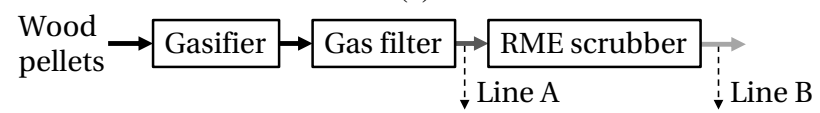

(b)

Figure 5: Schematic overview of case studies. (a) Model gas; (b) real producer gas.

\subsubsection{Model Gas}

Experiments in the model gas study were performed in collaboration with KIT (Karlsruhe, Germany) which extended tar reforming experiments previously conducted at PSI [38, 41]. The set-up comprised a gas mixing section where a set of mass flow controllers (MFC) was used to create a model gas containing $\mathrm{H}_{2}, \mathrm{CH}_{4}$ and $\mathrm{N}_{2}$. The steam content was adjusted by passing the gas through a steam saturator with a controlled outlet temperature. Afterwards, $\mathrm{H}_{2} \mathrm{~S}$ was added for selected experiments to investigate its effect on catalyst performance regarding tar compound conversion. A defined model tar mixture was fed to the pre-heated inlet gas stream by means of a syringe pump (PHD 2000, Harvard Apparatus). The mixture consisted of naphthalene dissolved in toluene. Naphthalene is typically present at high concentrations (60-1200 ppmv) in producer gas [38]. It was chosen as a representative for class 4 tar compounds. Toluene, replacing benzene for reasons of safer handling, was chosen as a representative of class 3 tar compounds [42]. The resulting gas mixture was sent to a catalyst coated monolith, in the following called reformer, at a temperature of $750^{\circ} \mathrm{C}$. Sampling of the gas was performed by two liquid quench sampling systems before (line A) and after (line B) the reformer, allowing for on-line observation of tar compound decomposition. Tubing before/after the reactor and the sampling ports were heated to $120^{\circ} \mathrm{C}$ to prevent loss of analytes. A summary of the experimental conditions of three experiments presented in this work is provided in table 1 .

Table 1: Experimental conditions of model gas case study

\begin{tabular}{|c|c|c|c|c|c|c|c|c|c|}
\hline \multirow[b]{3}{*}{ Exp. } & \multirow[b]{3}{*}{ Start (hh:mm) } & \multirow[b]{3}{*}{$\mathrm{T}(\mathrm{C})$} & \multicolumn{7}{|c|}{ Gas inlet composition } \\
\hline & & & \multicolumn{4}{|c|}{ (vol.\%) } & \multicolumn{3}{|c|}{$(\mathrm{ppmv})$} \\
\hline & & & $\mathrm{H}_{2}$ & $\mathrm{CH}_{4}$ & $\mathrm{H}_{2} \mathrm{O}$ & $\mathrm{N}_{2}$ & $\mathrm{H}_{2} \mathrm{~S}$ & Toluene & Naphthalene \\
\hline M1 & $14: 15$ & & & & & & 3800 & & \\
\hline M2 & $14: 55$ & 750 & 37 & 4 & 15 & 42 & 0 & 100 & 20 \\
\hline M3 & $15: 50$ & & & & & & 0 & 0 & 0 \\
\hline
\end{tabular}

\subsubsection{Real Producer Gas}

Measurements were taken at a pilot-plant (Pfaffenhofen, Germany) for gasification of wood pellets [43]. The plant features a heatpipe-reformer, designed for $500 \mathrm{~kW}$ thermal input. The 
pressurized raw gas, exiting the gasifier is cooled down to $60-75^{\circ} \mathrm{C}$, passed through a particulate filter and a rapeseed methyl ester (RME) scrubber for gas cleaning, before it is sent to a gas engine for electricity production. Liquid quench samples were taken using one liquid quench sampling system, connected to either line A or B. The sampling point A was located before the RME scrubber. Samples taken after the scrubber (gas temperature $40^{\circ} \mathrm{C}$ ) at sampling point $\mathrm{B}$ allowed to qualitatively evaluate its effectiveness.

\subsection{Tar Quantification}

\subsubsection{Analysis of $U V$-Vis Spectra}

In this work, UV-Vis spectra of samples taken on lines A and B of the model gas and line $\mathrm{B}$ of the real producer gas case study were analysed quantitatively. Absorbance spectra of five identified tar compounds in these streams are plotted at different concentrations in fig. 6.

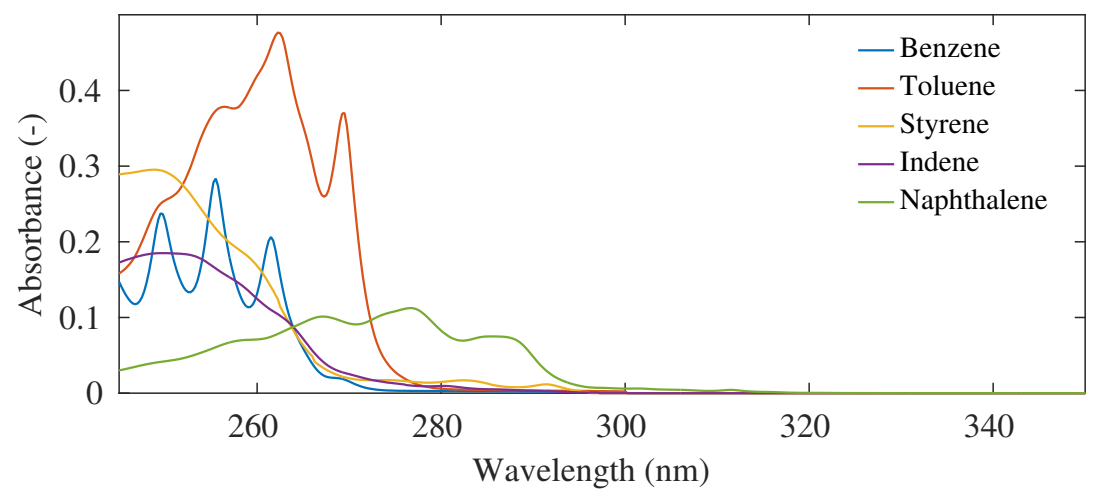

Figure 6: Absorbance spectra (path length $2 \mathrm{~mm}$ ) of five tar compounds in 2-propanol (concentrations for benzene and toluene: $10 \mathrm{mmol} / \mathrm{l}$, for styrene, indene and naphthalene: $0.1 \mathrm{mmol} / \mathrm{l}$ )

Since spectra of the tar compounds overlap it is problematic to perform an univariate calibration. Therefore, two multivariate regression approaches were followed in both case studies. CLS, a as well-known calibration method, was chosen for the model gas case study [44]. Two possible limitations of this approach have to be considered. It is assumed that all tar compounds in the liquid sample are known. The presence of not considered UV-Vis active compounds can result in biased results as their contribution to the absorbance is assigned to the calibrated tar compounds. An additional limitation can result from collinearity of the analysed tar compound spectra. A high degree of collinearity will result in an unstable system of equations, causing large variations in the solution for only small changes in the measured spectrum [45]. In case of the model gas case study, previous experiments [38] have shown that the qualitative composition of tar compounds, represented by benzene, toluene and naphthalene, is not subject to change (i.e. possible reaction products such as xylene and styrene can be neglected). UV-Vis spectra of these three compounds show spectral overlaps, but the degree of collinearity is low. The CLS approach can therefore be used in this case study. When applied to another system, these assumptions have to be verified again.

In the real producer gas case study, liquid samples taken at line B contain at least those five compounds depicted in fig. 6 . Especially styrene and indene show a high degree of collinearity (see fig. SI.4). The CLS approach is therefore not a viable option for this application and a different 
calibration method was chosen. Because of its ability to overcome problems like collinearity and interactions, PLS regression has been widely used for such cases of first-order multivariate calibration [46, 47] and was therefore chosen for this application. A good overview of the method is given by Martens and Naes [48]. Handling of data and implementation of spectra decomposition by CLS and PLS in this work was performed in MATLAB 2015a (The MathWorks).

\subsubsection{Partial Least Squares Regression}

Five tar compounds (benzene, toluene, styrene, indene and naphthalene) are expected to play a major role (see chapter 3.2) when evaluating spectra of gas, exiting the gas scrubber. A calibration set, containing these five compounds as factors at three levels, was calculated according to a full factorial design $\left(3^{5}\right)$ [49]. The levels were varied between zero and an upper liquid concentrations expected in later applications (see table 2).

Table 2: Settings and validation results of PLS method ${ }^{1}$

\begin{tabular}{lrrrrr}
\hline & Benzene & Toluene & Styrene & Indene & Naphthalene \\
\hline Concentration, & 25 & 5 & 0.25 & 0.25 & 0.25 \\
upper level (mmol/l) & & & & & \\
\# PLS components & 4 & 5 & 5 & 5 & 4 \\
RMSEP (mmol/l) & 0.1 & 0.02 & 0.002 & 0.003 & 0.001 \\
REP $(\%)$ & 1 & 1 & 1.5 & 2.5 & 0.6 \\
\hline
\end{tabular}

In the resulting set, each calibration spectrum represents the sum of absorbance spectra of the individual tar compounds according to Beer's law including the addition of Gaussian random noise $(0.5 \%)$. The spectral range was limited to $245-300 \mathrm{~nm}$ to exclude the noisier signal at high wavelengths, as it contains no useful information, and the non-linear range of the instrument at lower wavelengths. The root mean squared error (RMSE) is used as a measure of the differences between measured and predicted concentrations as defined in eq. (4). In this equation, the variables $c_{\text {meas }, j}$ and $c_{\text {pred }, j}$ refer to the measured and predicted concentration of the $j$ th of a total of $N$ test samples.

$$
\mathrm{RMSE}=\sqrt{\frac{\sum_{j=1}^{N}\left(c_{\text {meas }, j}-c_{\text {pred }, j}\right)^{2}}{N}}
$$

Based on this definition, both the later introduced RMSE of cross-validation (RMSE-CV) and RMSE of prediction (RMSE-P) can be calculated. In order to find the optimum PLS model, the number of PLS components for each tar compound was individually selected by means of a 10-fold cross-validation. For each number of PLS components and a given tar compound, the RMSE-CV was calculated. From the resulting plots, the optimum number of PLS components (ranging from 4-5) was chosen as a trade-off between prediction bias and variance by visual inspection (see fig. SI.5 and table 2) [50]. Validation of the PLS method was performed, using samples of an independent validation set. This set was created similarly to the calibration set,

\footnotetext{
${ }^{1}$ Upper level refers to highest liquid concentration expected in the real producer gas case study
} 
featuring a $6^{5}$ full factorial design. The prediction ability of the method was measured by means of the RMSE-P and the relative error of prediction (REP) in percent, as defined in eq. (5).

$$
\mathrm{REP}=100 \frac{\text { RMSE-P }}{\bar{c}_{\text {cal }}}
$$

In this equation, $\bar{c}_{c a l}$ refers to the mean concentration of each tar compound included in the validation set. Calculated RMSE-Ps and REPs are listed in table 2. Obtained parity plots can be found in Figure SI.6. For the evaluated method, the calculated REP vary between 0.6-2.5\% depending on the tar species.

\subsubsection{Reference Methods}

Qualitative analysis of liquid samples obtained from the liquid quench sampling system, was performed by a GC (6890, Hewlett-Packard) coupled with a MS (5973, Hewlett-Packard). A Supelco SLB-IL59 column ( $30 \mathrm{~m} \times 250 \mu \mathrm{m} \times 0.20 \mu \mathrm{m})$ was used for separation of tar compounds. Injection of $1 \mu \mathrm{l}$ samples was performed at a 10:1 split ratio with a $\mathrm{He}$ carrier gas flow of $1 \mathrm{ml} / \mathrm{min}$. The oven temperature was varied as follows: $55^{\circ} \mathrm{C}$ (hold $3 \mathrm{~min}$ ) then $15^{\circ} \mathrm{C} / \mathrm{min}$ to $300^{\circ} \mathrm{C}$ (hold $15 \mathrm{~min})$. The MS was operated in scan mode (m/z 20-250) with an ionization energy of $70 \mathrm{eV}$. Quantitative analysis of selected tar species was performed by a GC (7890A, Agilent) equipped with an FID. Separation of tar compounds was done with an Agilent HP-5 column (30 m x $320 \mu \mathrm{m} \times 0.25 \mu \mathrm{m}) .1 \mu \mathrm{l}$ of sample was injected with a $25: 1$ split ratio and a He carrier gas flow of $1 \mathrm{ml} / \mathrm{min}$. The oven was operated as follows: $40^{\circ} \mathrm{C}$ (hold $6 \mathrm{~min}$ ) then $10^{\circ} \mathrm{C} / \mathrm{min}$ to $200^{\circ} \mathrm{C}$ (5 min). The FID was operated at $275^{\circ} \mathrm{C}$ with $\mathrm{H}_{2}(30 \mathrm{ml} / \mathrm{min})$, air $(300 \mathrm{ml} / \mathrm{min})$ and a make-up gas flow of $25 \mathrm{ml} / \mathrm{min} \mathrm{He}$. Calibration was performed at five concentration levels with solutions of known tar compound concentrations and 8 replicates each. An exemplary chromatogram is given in fig. SI.3. Relative standard deviations for quantification were below $10 \%$. 


\section{Results and Discussion}

In the following the developed UV-Vis method is applied to two case studies as defined in section 2.4 .

\subsection{Model Gas}

Figure $7 \mathrm{a}$ and fig. $7 \mathrm{~b}$ plot the absorbance as a function of wavelength and time before and after the reformer, respectively. The areas, separated by the dotted lines, represent time periods where liquid samples for GC-FID reference analysis were taken.

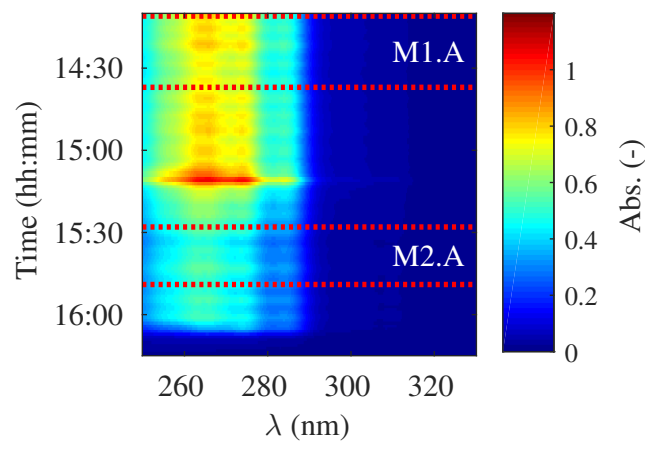

(a)

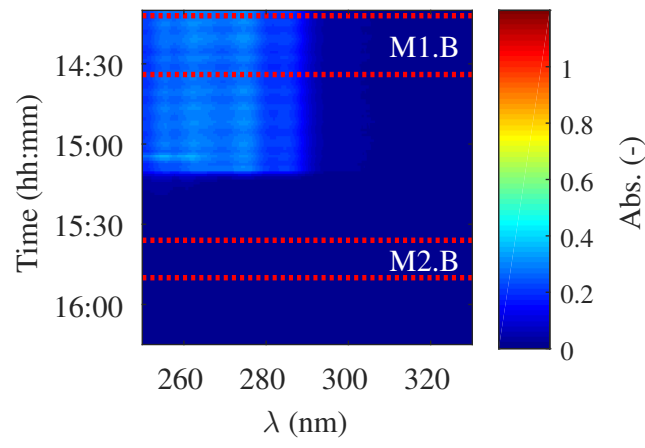

(b)

Figure 7: Plots of absorbance as a function of wavelength and time for the model gas case study. Time interval between dotted lines represents periods where different liquid samples for later GC-FID analysis were collected. (a) Before reformer (line A); (b) after reformer (line B).

Already at this point, the plots can provide some qualitative information. Both show absorbance features in the range $250-290 \mathrm{~nm}$, indicating the presence of light aromatic compounds (class 3 ). They also show a synchronous timely variation in absorbance, which can be related to the change in experimental conditions given in table 1. The absorbance in fig. 7a is generally higher than in fig. 7b. Assuming similar liquid quench sampling system operating conditions, this indicates a change in tar composition and/or a decrease in tar compound concentration caused by the reformer. The actual reason can only be elucidated after determining the individual tar compound contributions to the spectra. To achieve this, the individual tar compound concentrations in the liquid phase were determined by CLS. Using eq. (1), these can be related to their actual gas phase concentrations. The resulting tar compound gas concentrations versus time are presented by lines in fig. $8 \mathrm{a}$ and fig. 8 b.

Vertical lines in these plots represent the boundaries between different experimental settings (see table 1) whereas grey shaded areas represent time windows used to take liquid samples. Diamond shaped markers indicate tar compound gas concentrations obtained from GC-FID analysis. In the following, some general remarks on the concentration plots are made first and the results obtained by the UV-Vis and GC-FID method will be compared thereafter. Finally, the performance of the catalyst is briefly discussed. The concentration profiles show a response delay to changes in experimental conditions caused by the liquid quench sampling systems residence time characteristics, as discussed in section 2.2.1. Pulsations in predicted gas concentrations are caused by fluctuations in the gas flow entering the reformer, also indicated by MFC flow readings varying with a similar frequency. The peak at time 15:07 is caused by a momentary decrease in 


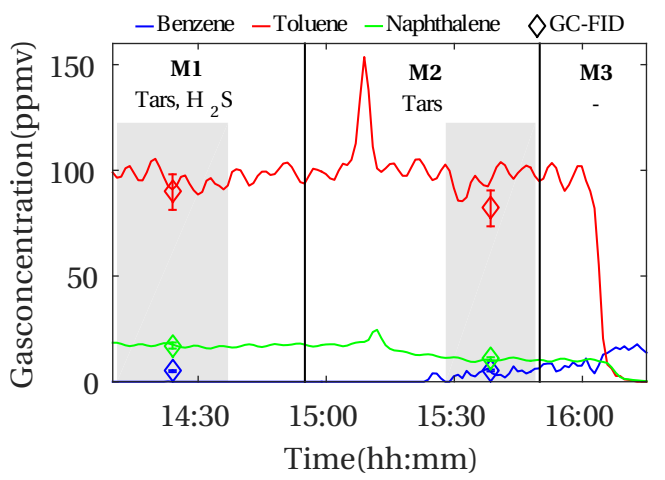

(a)

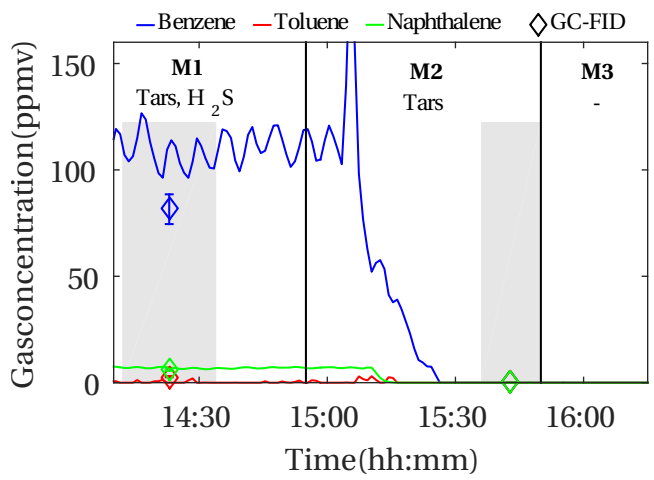

(b)

Figure 8: Vertical lines indicate boundaries between different experimental settings. The grey shaded areas represent time periods used to take liquid samples for later analysis. Diamond shaped markers represent GC-FID measurements. (a) Gas concentration at reformer inlet (line A); (b) gas concentration at reformer outlet (line B).

total gas flow as the $\mathrm{H}_{2} \mathrm{~S}$ addition was stopped. The observed behavior illustrates the advantages of on-line UV-Vis detection compared to off-line analytical tools. It allows to examine transient processes whereas off-line methods will only provide an average of such temporal fluctuation over several minutes. In order to evaluate the UV-Vis method, predicted concentrations were averaged for time periods for which liquid samples had been taken.

Table 3: Results of model gas case study ${ }^{2}$

\begin{tabular}{rrrrrrrr}
\hline & \multicolumn{3}{c}{ GC-FID $(\mathrm{mmol} / \mathrm{l})$} & & \multicolumn{3}{c}{ UV-Vis (mmol/l) } \\
\cline { 2 - 4 } \cline { 6 - 7 } Exp. & Benzene & Toluene & Naphthalene & & Benzene & Toluene & Naphthalene \\
\hline M1.A & $0.22 \pm 0.02$ & $3.2 \pm 0.3$ & $0.59 \pm 0.05$ & & $(0.3 \pm 1.3) 10-3$ & $3.4 \pm 0.2$ & $0.61 \pm 0.02$ \\
M1.B & $3.5 \pm 0.3$ & $0.10 \pm 0.01$ & $0.25 \pm 0.02$ & & $4.7 \pm 0.4$ & $0.01 \pm 0.03$ & $0.30 \pm 0.01$ \\
M2.A & $0.24 \pm 0.02$ & $2.9 \pm 0.3$ & $0.37 \pm 0.03$ & & $0.14 \pm 0.06$ & $3.4 \pm 0.2$ & $0.38 \pm 0.02$ \\
M2.B & b.d.l. & b.d.l. & b.d.l. & 0 & 0 & 0 \\
\hline
\end{tabular}

This allowed for a direct comparison of UV-Vis and GC-FID derived concentrations. In experiment M1, at the reformer inlet (M1.A), both toluene and naphthalene concentrations are well estimated by the UV-Vis method with prediction errors within the measurement uncertainty of the GC-FID method. The low concentration ( 5 ppmv) of benzene was not detected, however. At the reformer outlet (M1.B), benzene (33\% prediction error) and naphthalene (22\%) are predicted reasonably well, while the low concentration of toluene ( $2 \mathrm{ppmv})$ is not detected. In experiment M2, all three tar compounds are detected at the reformer inlet (M2.A). Toluene is overestimated $(19 \%)$ while benzene is underestimated $(-41 \%)$ at low concentration levels. The predicted concentration of naphthalene is good ( $4 \%$ error). The non-existence of tar compounds at the reformer outlet (M2.B) is predicted by both methods. From the above results it is apparent that prediction errors for toluene and benzene at low concentrations are higher than in the case of naphthalene. This can be attributed to the extinction coefficients of naphthalene which are two orders of magnitude higher than those of the class 3 tar compounds. Consequently, a smaller

b.d.1.: below detection limit 
concentration of naphthalene will suffice to achieve comparable absorbances and measurement errors. The presented UV-Vis method can be a valuable tool when immediate information for assessing the performance of catalysts is needed. In experiment M1, inlet gas phase concentrations of toluene and naphthalene are close to the set ones, while that of benzene is almost zero. Thermal cracking of tar compounds before the reformer inlet can therefore be neglected under the given experimental conditions. Based on their concentration profiles, the conversion of the reaction educts, toluene and naphthalene, is calculated and plotted in fig. 9a.

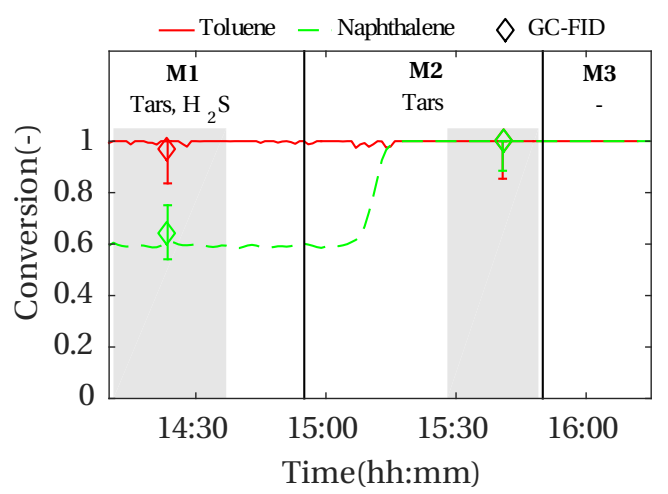

(a)

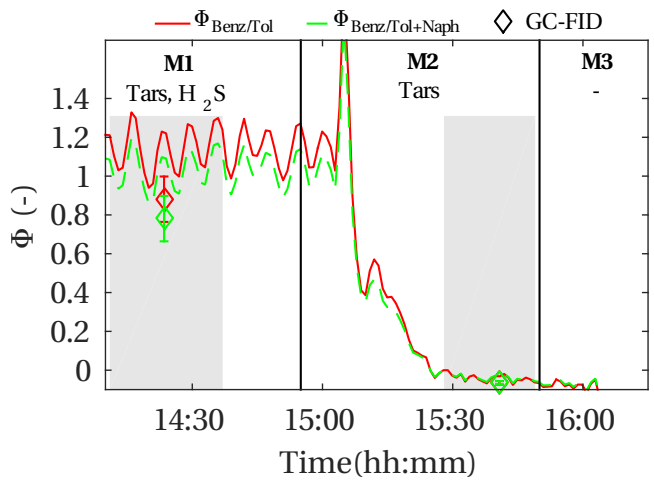

(b)

Figure 9: Vertical lines indicate boundaries between different experimental settings. The grey shaded areas represent time periods used to take liquid samples for later analysis. Diamond shaped markers represent GC-FID measurements. (a) Calculated conversion of toluene and naphthalene; (b) calculated overall fractional yields towards benzene as defined in eqs. (6) and (7).

Across the reformer, almost all toluene $(>97 \%)$ and $61 \%$ of naphthalene are converted. High exit gas concentrations of benzene indicate that dealkylation of toluene might be a major reaction path. In fact, the overall fractional yield $\Phi_{B e n z / T o l}$, defined in eq. (6) and plotted in fig. $9 \mathrm{~b}$, indicates that the majority of toluene is converted to benzene [51].

$$
\Phi_{\text {Benz } / \text { Tol }}=\frac{F_{\text {Benz,out }}-F_{\text {Benz,in }}}{F_{\text {Tol,in }}-F_{\text {Tol,out }}}
$$

In this equation, $F_{i}$ refer to the inlet or outlet molar flows of the individual tar compounds. Results, obtained by the UV-Vis method, overestimate the fractional yield due to an overestimated outlet concentration of benzene. Assuming that the decomposition of naphthalene can form benzene as well [52], an overall fractional yield $\Phi_{\text {Benz/Tol+Naph }}$ of benzene from toluene and naphthalene can be defined as in eq. (7).

$$
\Phi_{\text {Benz/Tol }+ \text { Naph }}=\frac{F_{\text {Benz,out }}-F_{\text {Benz,in }}}{\left(F_{\text {Tol,in }}-F_{\text {Tol,out }}\right)+\left(F_{\text {Naph,in }}-F_{\text {Naph,out }}\right)}
$$

Based on GC-FID results, it was found that $78 \%$ of the toluene and naphthalene measured at the reactor inlet have been converted to benzene. Further reaction products from toluene and naphthalene decomposition were not accessible to GC-FID and UV-Vis measurements. Because 
no experiments, containing the individual tar compounds, were performed, the actual contribution of naphthalene to the exiting benzene cannot be estimated.

As the supply of $\mathrm{H}_{2} \mathrm{~S}$ is ceased in experiment M2, a slight decrease in toluene and naphthalene inlet concentration is accompanied by an increase in benzene concentration. At the reformer outlet, no tars can be detected, resulting in full conversion. When the tar supply is stopped too, (experiment M3), the tar compound inlet concentrations decline as well, with the exception of benzene. Its concentration increases, only to fall off after approximately $15 \mathrm{~min} 15 \mathrm{~min}$. Experiments M1 and M2 show that $\mathrm{H}_{2} \mathrm{~S}$, which is in part reversibly bound to active sites of the catalyst [53], has a major effect on tar conversion. When $\mathrm{H}_{2} \mathrm{~S}$ is present, naphthalene is only partially converted, while the majority of toluene is converted to benzene. As soon as the $\mathrm{H}_{2} \mathrm{~S}$ supply is stopped, all tar compounds are decomposed [54].

\subsection{Real Producer Gas}

Next to catalytic reforming, absorption of tars by a solvent at low temperatures $\left(i 100^{\circ} \mathrm{C}\right)$ presents an alternative secondary method for tar removal. Different scrubber designs and solvents have been investigated. Among them, RME scrubbers have proven to be a successful option [55]. GC-MS chromatograms of liquid samples (see fig. SI.9), taken before and after an RME scrubber, show complex mixtures of hydrocarbons. At the scrubber inlet, more than 20 tar compounds were detected, ranging from class 3 tar compounds such as benzene to heavy polycyclic aromatic hydrocarbon (class 5) like fluoranthene. The scrubber removes tar compounds with molecular weights typically larger than naphthalene from the gas stream. This is in agreement with previous studies which report increased removal performances for increasing molecular weight of tar compounds $[43,56,57]$. An exemplary off-line UV-Vis spectrum of a diluted liquid sample (R1.A), taken before the RME scrubber, is presented in fig. 10.

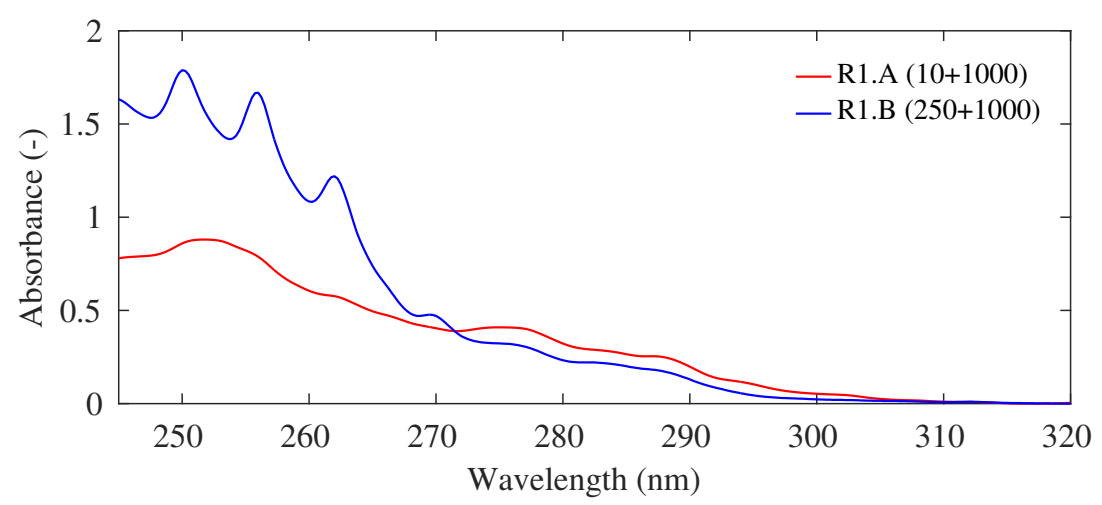

Figure 10: Absorbance spectra of samples taken before (R1.A, diluted $10 \mu \mathrm{l}$ sample $+1000 \mu 1$ solvent) and after (R1.B, diluted $250 \mu \mathrm{l}$ sample $+1000 \mu \mathrm{l}$ solvent) the RME scrubber

While features at $276 \mathrm{~nm}$ and $287 \mathrm{~nm}$ can suggest the presence of naphthalene at high concentrations, the high spectral overlap at lower wavelengths complicates quantification of further compounds significantly. On-line UV-Vis spectra, taken at the RME scrubber outlet are plotted in fig. 11a.

Visual inspection of the plot allows for a qualitative analysis of the tar composition as a function of time. As such, it displays the ability of the developed method to on-line monitor 


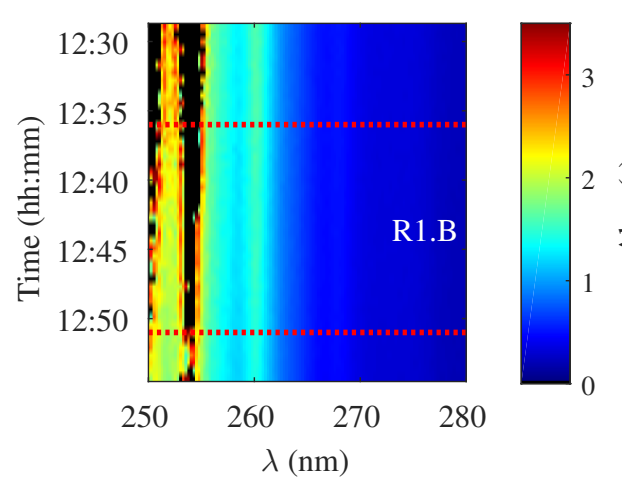

(a)

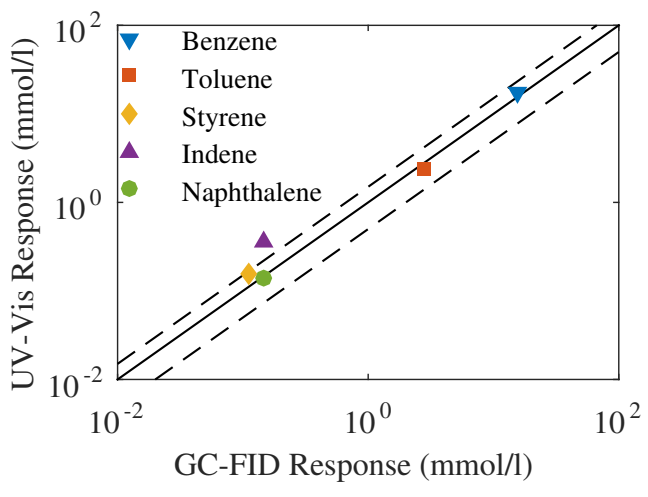

(b)

Figure 11: (a) Plot of absorbance versus wavelength and time at RME scrubber outlet. The area enclosed by the dotted lines represents the time window where a liquid sample for later GC-FID analysis was taken. Black colours indicate regions where the maximum absorbance of the instrument was exceeded; (b) Parity plot of tar concentrations, measured in sample R1.B by GC-FID and UV-Vis (PLS). The dashed lines represent the $\pm 50 \%$ deviation lines.

the stability of pilot-scale processes. The dotted lines represent the time span between which a liquid sample was taken. The figure shows a slight decrease in absorbance with time. Absorption features below $270 \mathrm{~nm}$ indicate the presence of aromatic compounds. Between 250-255 nm, the observed absorbance is high $(i 2.5)$ and pixels marked black represent areas where the maximum absorbance of the instrument was exceeded. A liquid sample (R1.B) was additionally analysed off-line by an UV-Vis spectrometer (after dilution) and GC-FID (figs. 10 and 11b). Quantification of its tar compounds was performed by the PLS method. The results of obtained liquid phase concentrations are plotted as a parity plot in fig. 11b. Benzene, toluene, styrene and naphthalene are estimated well with prediction errors below $27 \%$. Indene, with its few distinctive features and rather low concentration, is predicted with large error of 59\%. However, it can still serve as a valuable estimate. Based on eq. (1), gas phase concentrations obtained with the PLS method were calculated to range from $0.9 \mathrm{ppmv}$ for naphthalene to $113 \mathrm{ppmv}$ in case of benzene (for summary, see Table SI.5).

\section{Conclusions}

In this study, a new on-line UV-Vis method was developed and proved to be a readily applicable measurement method for the detection of tar compounds in process gases obtained from wood gasification Two cases of application for the method were tested. In situations where the tar composition is diverse (e.g. before tar treatment), quantitative analysis is impeded by several factors. A high number and spectral overlap (collinearity) of tar compounds will cause increased variances of the obtained concentrations. Because the product of concentration and extinction coefficient of tar compounds can span over orders of magnitude, tar compounds with high absorbance might mask the presence of tar compounds with smaller ones. In such situations the method cannot replace more expensive on-line analytical tools, but provide qualitative information for process monitoring. Strip charts, plotting the absorbance of selected wavelengths versus time, can give an indication on the process stability. The absence of high molecular tar compounds, which are known to cause condensation issues, can easily be monitored because they tend to 
absorb light at higher wavelengths [31]. Quantitative analysis becomes feasible when the number of tar compounds is limited (e.g. after tar treatment). Tar compound concentration profiles across a lab-scale reformer were obtained by means of a classical least squares approach for spectra decomposition. Concentration predictions for the three involved tar compounds benzene, toluene and naphthalene were comparable to those obtained by GC-FID as a reference method. More complex spectra, collected after a pilot-scale gas scrubber, were analysed by a partial least squares calibration and showed good results for five tar compounds.

\section{Acknowledgments}

P. Edinger thanks T. Schildhauer (PSI) for valuable discussions. The authors thank H. Wagenbach (PSI) for technical assistance involving experiments performed at KIT and J. Regler for conducting experiments at the pilot-plant in Pfaffenhofen as well as J. Witte (PSI) for experimental assistance. The authors thank the ITC group at KIT (Karlsruhe), including H. Leibold, A. Linek, R. Mai and G. Schuller for access to experimental equipment and technical assistance. The authors acknowledge financial support from the SNF within the National Research Programme (NRP, project 66) and Competence Center Energy and Mobility (CCEM, Syngas Diagnosis). The exchange in the frame of the Swiss Competence Center for Energy Research (SCCER; BIOSWEET) is also acknowledged.

\section{References}

[1] P. McKendry, Energy production from biomass (part 1): overview of biomass, Bioresource Technology 83 (2002) 37-46.

[2] H. Cui, S. Q. Turn, V. Keffer, D. Evans, T. Tran, M. Foley, Contaminant estimates and removal in product gas from biomass steam gasification, Energy \& Fuels 24 (2010) 1222-1233.

[3] K. Maniatis, A. Beenackers, Tar protocols. iea bioenergy gasification task, Biomass \& Bioenergy 18 (2000) 1-4.

[4] T. A. Milne, N. Abatzoglou, R. J. Evans, Biomass gasifier" tars": their nature, formation, and conversion. Golden (Colorado): National Renewable Energy Laboratory, 1998.

[5] Z. Ud Din, Z. A. Zainal, Biomass integrated gasification-sofc systems: Technology overview, Renewable and Sustainable Energy Reviews 53 (2016) 1356-1376.

[6] P. V. Aravind, W. de Jong, Evaluation of high temperature gas cleaning options for biomass gasification product gas for solid oxide fuel cells, Progress in Energy and Combustion Science 38 (2012) 737-764.

[7] J. A. Ruiz, M. C. Juarez, M. P. Morales, P. Munoz, M. A. Mendivil, Biomass gasification for electricity generation: Review of current technology barriers, Renewable \& Sustainable Energy Reviews 18 (2013) 174-183.

[8] J. Kiel, S. Van Paasen, J. Neeft, L. Devi, K. Ptasinski, F. Janssen, R. Meijer, R. Berends, H. Temmink, G. Brem, Primary measures to reduce tar formation in fluidised-bed biomass gasifiers, ECN, ECN-C-04-014 (2004).

[9] Y. Shen, J. Wang, X. Ge, M. Chen, By-products recycling for syngas cleanup in biomass pyrolysis - an overview, Renewable and Sustainable Energy Reviews 59 (2016) 1246-1268.

[10] L. Devi, K. J. Ptasinski, F. J. J. G. Janssen, A review of the primary measures for tar elimination in biomass gasification processes, Biomass and Bioenergy 24 (2003) 125-140.

[11] S. Anis, Z. A. Zainal, Tar reduction in biomass producer gas via mechanical, catalytic and thermal methods: A review, Renewable and Sustainable Energy Reviews 15 (2011) 2355-2377.

[12] P. J. Woolcock, R. C. Brown, A review of cleaning technologies for biomass-derived syngas, Biomass \& Bioenergy 52 (2013) 54-84.

[13] S. Van Paasen, J. Kiel, J. Neeft, H. Knoef, G. Buffinga, U. Zielke, K. Sjostrom, C. Brage, P. Hasler, P. Simell, Guideline for sampling and analysis of tar and particles in biomass producer gases, ECN (2002).

[14] C. Brage, Q. Yu, G. Chen, K. Sjöström, Use of amino phase adsorbent for biomass tar sampling and separation, Fuel 76 (1997) 137-142.

[15] M. Israelsson, M. Seemann, H. Thunman, Assessment of the solid-phase adsorption method for sampling biomassderived tar in industrial environments, Energy \& Fuels 27 (2013) 7569-7578.

[16] S. Osipovs, Comparison of efficiency of two methods for tar sampling in the syngas, Fuel 103 (2013) $387-392$. 
[17] S. Karellas, J. Karl, Analysis of the product gas from biomass gasification by means of laser spectroscopy, Optics and Lasers in Engineering 45 (2007) 935-946.

[18] R. Sun, N. Zobel, Y. Neubauer, C. Cardenas Chavez, F. Behrendt, Analysis of gas-phase polycyclic aromatic hydrocarbon mixtures by laser-induced fluorescence, Optics and Lasers in Engineering 48 (2010) 1231-1237.

[19] A. Dieguez-Alonso, A. Anca-Couce, N. Zobel, On-line tar characterization from pyrolysis of wood particles in a technical-scale fixed-bed reactor by applying laser-induced fluorescence (lif), Journal of Analytical and Applied Pyrolysis 102 (2013) 33-46.

[20] E.-J. Shin, M. R. Nimlos, R. J. Evans, Kinetic analysis of the gas-phase pyrolysis of carbohydrates, Fuel 80 (2001) 1697-1709.

[21] D. L. Carpenter, S. P. Deutch, R. J. French, Quantitative measurement of biomass gasifier tars using a molecular-beam mass spectrometer: Comparison with traditional impinger sampling, Energy \& Fuels 21 (2007) 3036-3043.

[22] M. K. Akalın, S. Karagöz, Analytical pyrolysis of biomass using gas chromatography coupled to mass spectrometry, TrAC Trends in Analytical Chemistry 61 (2014) 11-16.

[23] A. L. Brown, D. C. Dayton, M. R. Nimlos, J. W. Daily, Characterization of biomass pyrolysis vapors with molecular beam, single photon ionization time-of-flight mass spectrometry, Chemosphere 42 (2001) 663-669.

[24] F. Mühlberger, R. Zimmermann, A. Kettrup, A mobile mass spectrometer for comprehensive on-line analysis of trace and bulk components of complex gas mixtures: parallel application of the laser-based ionization methods vuv single-photon ionization, resonant multiphoton ionization, and laser-induced electron impact ionization, Analytical Chemistry 73 (2001) 3590-3604.

[25] F. Defoort, S. Thiery, S. Ravel, A promising new on-line method of tar quantification by mass spectrometry during steam gasification of biomass, Biomass and Bioenergy 65 (2014) 64-71.

[26] L. Jia, Y. Le Brech, G. Mauviel, F. Qi, M. Bente-von Frowein, S. Ehlert, R. Zimmermann, A. Dufour, Online analysis of biomass pyrolysis tar by photoionization mass spectrometry, Energy \& Fuels 30 (2016) 1555-1563.

[27] S. Van Paasen, H. Boerrigter, J. Kuipers, A. Stokes, F. Struijk, A. Scheffer, Tar dewpoint analyser. for application in biomass gasification product gases, ECN (2005).

[28] O. Moersch, H. Spliethoff, K. R. G. Hein, Tar quantification with a new online analyzing method, Biomass and Bioenergy 18 (2000) 79-86.

[29] M. Ahmadi, C. Brage, K. Sjoestroem, K. Engvall, H. Knoef, B. Van de Beld, Development of an on-line tar measurement method based on photo ionization technique, Catalysis Today 176 (2011) 250-252.

[30] M. Ahmadi, H. Knoef, B. Van de Beld, T. Liliedahl, K. Engvall, Development of a PID based on-line tar measurement method - proof of concept, Fuel 113 (2013) 113-121.

[31] H.-H. Perkampus, UV-VIS Atlas of Organic Compounds, VCH, Weinheim, 2 edition, 1992.

[32] F. Patuzzi, D. Roveda, T. Mimmo, J. Karl, M. Baratieri, A comparison between on-line and off-line tar analysis methods applied to common reed pyrolysis, Fuel 111 (2013) 689-695.

[33] M. Di Marcello, K. Gallucci, S. Rapagna, R. Gruber, M. Matt, Hptlc and UV spectroscopy as innovative methods for biomass gasification tars analysis, Fuel 116 (2014) 94-102.

[34] T. Weide, V. Guschin, W. Becker, S. Koelle, S. Maier, S. Seidelt, Analysis of pure tar substances (polycyclic aromatic hydrocarbons) in the gas stream using ultraviolet visible (UV-vis) spectroscopy and multivariate curve resolution (MCr), Applied Spectroscopy 69 (2015) 143-153.

[35] M. D. K. Rechulski, J. Schneebeli, S. Geiger, T. J. Schildhauer, S. M. A. Biollaz, C. Ludwig, Liquid-quench sampling system for the analysis of gas streams from biomass gasification processes. part 1: Sampling noncondensable compounds, Energy \& Fuels 26 (2012) 7308-7315.

[36] M. D. K. Rechulski, J. Schneebeli, S. Geiger, T. J. Schildhauer, S. M. A. Biollaz, C. Ludwig, Liquid-quench sampling system for the analysis of gas streams from biomass gasification processes. part 2: Sampling condensable compounds, Energy \& Fuels 26 (2012) 6358-6365.

[37] P. Edinger, High Temperature Conversion of Sulfur Containing Hydrocarbons and Tars, Master's thesis, ETH Zurich, 2012.

[38] U. Rhyner, P. Edinger, T. J. Schildhauer, S. M. A. Biollaz, Experimental study on high temperature catalytic conversion of tars and organic sulfur compounds, International Journal of Hydrogen Energy 39 (2014) $4926-4937$.

[39] G. I. Egorov, V. N. Afanas'ev, A. M. Kolker, Vtx properties of the system water-2-propanol in the range 275.15338.15 K, Russian Journal of General Chemistry 74 (2004) 171-173.

[40] O. Levenspiel, Chemical reaction engineering, Wiley, New York, 3 edition, 1999.

[41] U. Rhyner, P. Edinger, T. J. Schildhauer, S. M. A. Biollaz, Applied kinetics for modeling of reactive hot gas filters, Applied Energy 113 (2014) 766-780.

[42] S. Srinivas, R. P. Field, H. J. Herzog, Modeling tar handling options in biomass gasification, Energy \& Fuels 27 (2013) 2859-2873

[43] G. Gallmetzer, P. Ackermann, A. Schweiger, T. Kienberger, T. Gröbl, H. Walter, M. Zankl, M. Kroener, The agnion heatpipe-reformer-operating experiences and evaluation of fuel conversion and syngas composition, Biomass Conversion and Biorefinery 2 (2012) 207-215. 
[44] C. L. Lawson, R. J. Hanson, Solving least squares problems, Classics in applied mathematics, SIAM, Philadelphia, 1995.

[45] D. A. Belsley, E. Kuh, R. E. Welsch, Regression diagnostics identifying influential data and sources of collinearity, Wiley series in probability and mathematical statistics Applied probability and statistics, Wiley, New York etc., 1980.

[46] S. Wold, M. Sjoestroem, L. Eriksson, Pls-regression: a basic tool of chemometrics, Chemometrics and Intelligent Laboratory Systems 58 (2001) 109-130.

[47] A. C. Olivieri, Practical guidelines for reporting results in single- and multi-component analytical calibration: A tutorial, Analytica Chimica Acta 868 (2015) 10-22.

[48] H. Martens, T. Næs, Multivariate calibration, Wiley, Chichester, 1992.

[49] G. E. P. Box, J. S. Hunter, W. G. Hunter, Statistics for experimenters design, innovation, and discovery, Wiley series in probability and statistics, Wiley-Interscience, Hoboken, N.J., $2^{\text {nd }}$ edition, 2005.

[50] N. M. Faber, A closer look at the bias-variance trade-off in multivariate calibration, Journal of Chemometrics 13 (1999) 185-192.

[51] P. A. Simell, J. O. Hepola, A. O. I. Krause, Effects of gasification gas components on tar and ammonia decomposition over hot gas cleanup catalysts, Fuel 76 (1997) 1117-1127.

[52] Y.-1. Zhang, Y.-h. Luo, W.-g. Wu, S.-h. Zhao, Y.-f. Long, Heterogeneous cracking reaction of tar over biomass char, using naphthalene as model biomass tar, Energy \& Fuels 28 (2014) 3129-3137.

[53] C. H. Bartholomew, Mechanisms of catalyst deactivation, Applied Catalysis A: General 212 (2001) 17-60.

[54] J. Hepola, P. Simell, Sulphur poisoning of nickel-based hot gas cleaning catalysts in synthetic gasification gas - ii. chemisorption of hydrogen sulphide, Applied Catalysis B-Environmental 14 (1997) 305-321.

[55] R. Zwart, Gas Cleaning: Downstream Biomass Gasification: Status Report 2009, ECN, 2009.

[56] T. Phuphuakrat, T. Namioka, K. Yoshikawa, Absorptive removal of biomass tar using water and oily materials, Bioresource Technology 102 (2011) 543-549.

[57] E. Masurel, O. Authier, C. Castel, C. Roizard, Screening method for solvent selection used in tar removal by the absorption process, Environmental Technology 36 (2015) 2556-2567. 